\title{
English Spelling Errors Committed by the Blind
}

\author{
${ }^{1 *}$ Ni’matul Lailiyah, ${ }^{2}$ Iswahyuni, ${ }^{3}$ Alies Poetri Lintangsari \\ ${ }^{1}$ Special Education, Universitas Negeri Malang, Malang, Indonesia \\ ${ }^{2,3}$ English Education, Universitas Brawijaya, Malang, Indonesia
}

\begin{abstract}
Despite the outgrowing trend on assistive technology assisting blind student to be fully participate in education, the challenges remain in the area of English language learning. The inconsistency of the soundspelling relationship in English apparently triggers the spelling problems for the Blind student since he tends to encode syllables by as it sounded. This study aims to identify, classify and analyze the spelling errors committed by the blind students in learning English using the classification of NEFR (National Foundation for Educational Research) that comprises the aspects of omissions, substitutions, insertions, transpositions and grapheme substitution. Employing case study design, this research elaborate the spelling error committed by 1 blind EFL learner enrolling an Academic Writing course in English Language Education Program, Faculty of Cultural Studies, Universitas Brawijaya, Indonesia. The findings expose that the blind students tend to frequently do spelling error in the aspect of grapheme substitution followed by omissions, substitutions, and insertion. Some contributive factors that presumably affecting the errors are (1) lack exposure to the formation of the words, (2) inherent of language (silent letter, homophone and borrowing words), (3) different characteristics of L1 and L2, and (4) student's preferences on reading (use screen reader more than braille text). Thus, the exposure toward phonetics symbol and the sound-letter relationship in English should be more disseminated so the blind student is capable of having a correct spelling.
\end{abstract}

Keywords: Spelling Errors, Blind Student, English

\section{Research Background}

Inclusive education is one of the bridges for people with disabilities and without disabilities to get a chance to socialize each other. According to Barbotte et al, (2001, p.1047A) disability is a restriction or inability to perform an activity in the manner or within the range considered normal for a human being, mostly resulting from impairment. It is caused by accident, trauma, genetics or disease that may limit a person's mobility, hearing, vision, speech, or mental function. Universitas Brawijaya is one of the institutions which started to provide inclusive class for students with disability. Students with disability have different way to access lecturer's information. Deaf student, for instance, can get information visually with sign. However, blind student acquires information through sound. That way, Universitas Brawijaya provides assistant to

* Corresponding author: Ni'matul Lailiyah email: nimatullailiyahlia19@gmail.com

Published online at http://IJDS.ub.ac.id/2020- 1

Copyright (C) 2020 PSLD UB Publishing. All Rights Reserved assist the students with disability to involve in every activity.

Learners with no vision will have more difficulties to write the letter because blind encode syllables by the sound as the unity of word. The reading problem will affect their writing ability especially for words spelling such phenomena happen in any classes, including in language classroom. It is stated by Stein (2011) that in the second language (L2) classroom, especially spelling is often challenging for the visually impaired. There is evidence that children who are visually impaired are more likely to have difficulty achieving the levels of accuracy in spelling of their sighted peers (McCall, 1999).

For blind students reading skill which functions for acquiring and understanding vocabulary in the text has been replaced by listening using assistive technologies such as 'screen reader'. However, reading text is not the same as having it read aloud by 'text-tospeech' technology. While the content is available in both cases, orthographic information is lost when text is read by a screen 
reader (Stein, 2011). Orthographic or word form regularity refers to the way in which a language associates letters to sounds. It also deals with spelling. To learn how to read and write, the child must acquire detailed orthographic representations of regular and irregular words and access them globally (Frith, 1985, 1986).

As blind student tends to learn auditory, the subject of this study recognizes the word through sound then write as he heard. Lack of knowledge of written words which is important for the future educator will be an obstacle for blind student's carrier as an English teacher. Whereas, teachers which also researchers have to build writing skill to share their thought of teaching and experience into paperwork such as thesis, article, journal and etc. The Nation Commission Writing in America (2003, p.11) states that writing today is not a frill for the few, but an essential skill for the many. It means that it is important to have writing skill since educated people need to connect their knowledge to their experience into paper continually.

Thus, the recent study has to be held to identify, to classify and to analyze the spelling errors of a blind student. The aim is can be a reflection to the blind student who is observed, can be an information for stakeholder of the limitation of the blind in writing, and can be the inspiration for next researcher to find the strategy to help blind to learn spelling. The errors will be analyzed using spelling errors of (National Foundation for Educational Research) NFER's classification (cited in Cook, Vivian: 2004, p.124) which are Omissions, Substitutions, Insertions, Transpositions and, Grapheme substitution. The subject would be observed in his classroom setting especially in writing subject.

\section{Method}

This research belongs to the case study because it is to reveal the spelling errors of English words spelling on a blind student. The description was about the spelling errors produced by blind student in writing. This study also focuses on one special subject to be researched in depth. The focus data was the words composition of Academic Writing tasks. The subject of this research is a blind student at the fourth semester of English Department Universitas Brawijaya Malang. The subject can write and read in braille but he does not apply in learning English. He also uses assistive technology such as 'screen reader' in reading and asks peers/friends to write the tasks. Thus, he does not have much direct contact with English words that lead spelling errors. According to Budiarti (2018) positive support provided such as teacher and peers/friends can help student with visual impairment in handling challenges. However, the positive supports in any classes have to let the visual impairment to experience in writing.

The researchers begin with collecting the data which taken in the writing tasks. All the data collection which identified as inaccurate spelling was categorized to allow analysis of spelling errors. The data was analyzed by NFER's classification spelling errors. The Conclusion of data analysis was drawn in form of words based on spelling errors found.

\section{Findings}

The analysis of the finding showed that the research found a number of errors in three texts of the essay which was analyzed using NFER's classification spelling error. This discussion elaborates a deeper explanation about errors which was made by the subject.

Table 3.1 Total spelling errors according to NFER's classification

\begin{tabular}{|l|c|}
\hline \multicolumn{1}{|c|}{ Type of error } & $\begin{array}{c}\text { Frequency of } \\
\text { error }\end{array}$ \\
\hline Insertion & 9 \\
\hline Omission & 20 \\
\hline Substitution & 24 \\
\hline Transposition & 0 \\
\hline Grapheme substitution & 26 \\
\hline Total & $\mathbf{7 9}$ \\
\hline
\end{tabular}

The table above clearly figures out that out of 79 total errors were analyzed, the errors of grapheme substitution occupy the highest position with the number of error 26 words, followed by errors of substitution with 24 words. The various errors in the figures were the result spelling of blind student in Academic Writing class. The first text was the introductory paragraph of essay. The second text was developing paragraph of essay. The third was middle term of the essay. The researcher identified all the errors within the texts written by the subject. 
Based on the analysis, the subject particularly encoded words from the sound as syllable, not letter. The subject manipulates and associates a wide range of vowels and consonants combinations to form words based on existing phonetic language knowledge he has previously L1 or L2 for instance. These are some representatives of spelling error analysis committed by blind student which caused spelling error.

\section{A. Error of Insertion}

Insertion errors occurred mainly because of the addition of redundant letter(s) in a word. The first category of spelling errors was the insertion of [1] in 'allso' for 'also' and 'economicall' for 'economical'. The additional of [1] were caused by particular syllable that have same sound which called homophone like in the word 'all' and 'call' that he has succeded to write previously. Therefore, he or she familiarize with those previous sound and encode as basic the sound 'all' and 'call' to the target words (allso and economicall) which resulted in writing wrong spelling.

\section{B. Error of Omission}

Some omission errors and those most commonly found in the current study were the subject omit the double letter or doubling consonant for example 'suport', 'usualy' and 'afordeble' presumably the products of representing wrongly articulating 'support', 'usually' and 'affordeble'. These errors caused by his L1 (Bahasa Indonesia) which mostly do not have double letter of the words. Another common ommision errors are dropping the vowel in the word such as 'Lern' for 'Learn', 'Culturs' for 'Cultures' 'To' for 'Too', 'Ther' for 'Their', and 'Definitly' for 'Definitely. The subject wrote the words unsuccessfuly because mostly L1 (Bahasa Indonesia) has not silent letter and written as it is pronounced.

\section{Error of Substitution}

The errors of substitution were the second frequent errors in the written texts produced by the subject. These errors were the outcomes of substituting consonants more frequently than vowels, and they were mainly related to pronunciation for example the letter [f] write as [v] like in the word 'evects'(effect), benevit (benefit), and also in the same fashion, errors of substituting [c] with [s] in 'consern' for 'concern', 'prise' for 'price' and 'plases' for 'places' underlines the errors that occur as a result of having no systematic rule for representing the $/ \mathrm{s} /$ consonant with the [c] or [s] phonemes in the initial position. This is the reason why the participants substituted one for the other. These errors can be attributed to a failure to recognize the fact that English words have multiple correspondences between the sounds of the language and the letters that represent those sounds.

\section{Error of Transposition}

Transposition errors are missordering letter in a word. Transposition error is not found in the text written by the subject. Study conducted by Cook (2004) transposition errors included 'freind' for 'friend', 'thier' for 'their', and 'quite' for 'quiet'. In these errors, the misordering of the vowels 'ie' was the most frequent error, which corresponds.

\section{E. Error of Grapheme Substitution}

The errors of grapheme substitution were the most frequent errors in the written texts produced by the subject. The grapheme substitution errors are complex error of spelling. Most of those are found in more than one substitution. Those are mostly caused combination of external and internal information. Mak (1993) states that when words have low-quality referential models this crucially affects the acquisition process of reading and writing skills. Visual impairment children learn to read complete configurational units (e.g. words), and whatever the visual channel gets in incomplete or unclear form, the mind completes by using additional external (e.g., acoustic, contextual) and internal (e.g., a previously stored word-model) information. Visual impairment children acquire writing by a similar "completion strategy", and the resulting combination of incomplete input information and often non-reliable, previously stored information, appears to be a frequent source of spelling error. However, in this case, the subject only learns the sound of the words then associate sound to words by using additional external (the words he heard) and internal (previously stored word-model both L1 and L2) information. For instance, he wrote 'Sigared' for 'Cigarette', 'Inkrising' for 'Increasing', 'Scolarsheeps' for 'Schoolarships', 'Evects' for 'Efects', 'Genuen' for 'Genuine', 'Carasteristiks' for 'Characteristics', Tinagers for 'Teenagers', 
'Roul'for 'Role', 'Helt' for 'Health', 'Afordeble' for 'Affordable', 'Fisikly' for 'Phisically', 'Playn' for 'Plane', 'Eazyly' for 'Easily', 'Fier' for 'Fare', 'afordeble' for 'Affordable', and 'Pissfull' for 'Peaceful'. Some are caused by borrowing words of English that he wrote in L1 (Bahasa Indonesia) version. For instance, he wrote 'Positif' for 'Positive', 'Negatif' for 'Negative', and 'Bisnis' for 'Business'. Another is caused by homophone which has sound alike such as in the words 'Aloud' for 'Allowed', 'Witch' for 'Which', and 'Fill' for 'Feel'.

\section{Discussion}

Based on the analysis using NFER's (National Foundation for Educational Research) spelling error classification which are Omissions, Substitutions, Insertions, Transpositions and, Grapheme substitution, out of 5 types of errors, the subject faced 4 errors which are Omissions, Substitutions, Insertions, and Grapheme substitution. The results showed that error of Grapheme substitution was the highest portion of the error. Based on the analysis it is mostly caused by combination of external and internal information of phonetic knowledge because of deficit of visual memory so that, the subject spells words phonetically that are non-phonetic in configuration. If it is compared to sighted student who learns English according to the previous study conducted by Eid, et al (2015), it was found that errors of omission constituted the highest proportion of errors. It is caused by learners often associated a wide range of vowel and consonant combinations in an attempt to spell words accurately, sometimes even combining two distinct lexical items by overlapping vowels.

This study also found that blind learner which does not read braille in target language is more challenging to write because he does not have much direct exposure to the formation of the words resulting in spelling errors. Words formation need to be gained because it is skill to organize the words. It is in line with Savant (2000) that spelling ability is more closely related to organizational habits and other personality traits than our intelligence. So, it means that organizational skills influence spelling ability.

Instead of remembering the letters, the subject encodes the syllable of each word because he recognizes words as it is sounded.
This challenge the blind to spell the words that he already heard to the letter without experiencing to the letters directly. It can be assumed that blind who learn English with braille would have better spelling. It is proved by the previous study conducted by Christine Clark and Julia B. Stoner (2008). They compare the spelling skills of students who are braille readers to a normative sample. The test of written spelling was administered to the 23 students who are blind at various grade levels to ascertain their spelling ability. The result indicates no significant difference in spelling ability of both types of students. Thus, blind who is supported by braille and sighted students have equal ability in writing.

In this study, there are some factors contribute to the spelling errors committed by blind student. Based on the analysis and discussion, there are lack exposure to the formation of the words, inherent of language (silent letter, homophone and borrowing words), different characteristics of L1 and L2, and student's preferences on reading (use 'screen reader' more than braille text). The explanation elaborated as follows.

First, the subject is lack exposure to the word formation. The subject of the research does not use braille in exploring target language. Auditory input provides another way student can gain information. Auditory language triggers the creation of mental images that correspond with words (Barraga \& Erin, 1992). Mak (1993) states that when words have low-quality referential models this crucially affects the acquisition process of reading and writing skills. Visual impairment children learn to read complete configurational units (e.g. words), and whatever the visual channel gets in incomplete or unclear form, the mind completes by using additional external (e.g., acoustic, contextual) and internal (e.g., a previously stored word-model) information. Visual impairment children acquire writing by a similar "completion strategy", and the resulting combination of incomplete input information and often non-reliable, previously stored information, appears to be a frequent source of spelling mistakes or errors. In this study, the subject combines external (the words he heard) and internal (previously stored wordmodel both L1 and L2) information resulted in error spelling.

Second, inherent of language can contribute error spelling. Peterson (2010) states 
that English is one of the most difficult modern languages to learn to spell because of the evolution of word pronunciations over the centuries; the existence of many silent letters; the plethora of homonyms; the numerous rules for adding prefixes and suffixes, creating plural forms, and hyphenating words; and the hodgepodge of words from other languages that comprise it. The inherent language that subject faced are silent letter, homophone, and borrowing words.

Third, the subject whom researcher observed do not consider that the fact the both Bahasa Indonesia (L1) and English language (L2) have completely different characteristics on writing system. It is stated by Arinjaya (2014) that phonological systems of both languages Bahasa Indonesia (L1) and English language (L2) have some differences. It puts learners of L1 in much difficulty in learning L2, particularly in learning sound systems since L1 has its own sound systems that are different from any other languages, and so does L2. Since blind encode syllables by the sound as the unity of words, they tend to write the words as it is sounded. This affects their English spelling since English words are not spelled as it is sounded.

Lastly, student's preferences on reading which use 'screen reader' more than braille text to gain target language is affected to the spelling ability. Generally, in reading text, readers gain spelling information but the subject only gains the sound of the words, that way, blind loss of word formation in reading. It is supported by Stein (2011) while the content is available in both cases, orthographic information is lost when text is read by a screen reader. In this case of writing words, the writers could have drawn on their spelling knowledge, which was marked by their effort to correspond grapheme with phoneme. Thus, the lack of orthographic information cause by student's preferences can affect the errors in writing.

Thus, these factors could have contributed to the omission, substitution, insertion, transposition and grapheme substitution errors of the subject.

\section{Conclusions}

The result of analysis of NFER's (National Foundation for Educational Research) spelling error classification shows that the subject faced 4 errors which are Omissions, Substitutions, Insertions, and Grapheme substitution. The highest number of error is Grapheme substitution. It is caused by combination of external and internal information of phonetic knowledge because of deficit of visual memory so that, the subject spells words phonetically that are non-phonetic in configuration. In general, the process of spelling acquisition is by connecting with the letter of the words. For blind student, it is challenging where learner does not connect with the letters directly in exploring language which affecting to commit errors. It means that the subject is lack exposure to the word formation. The inherent of language causes spelling error for the learner. There are silent letter, homophone and borrowing words. Consequently, blind who interested in learning English should take into his consideration the fact the both Bahasa Indonesia and English language have completely different characteristics on writing system. In addition, subject's preferences such as reading using 'screen reader' more than braille text contributes the error spelling. The additional external (the words he heard) and internal (previously stored word-model both L1 and L2) information resulted in error spelling. Accordingly, based on the results of this study, the subject committed spelling errors due to many factors such as (1) lack exposure to the word formation, (2) inherent of language (silent letter, homophone and borrowing words), (3) different characteristics of L1 and L2, and (4) student's preferences on reading (use screen reader more than braille text).

Based on the findings of the study, the researcher suggests for blind English learner to find his/her own strategy and get more exposure to written works. The blind learner can write his own work without assisting by learning assistant but using technological help on computer. Instead of using automatic spelling correction in computer, the learner can use sounding out technique to make sure that the word is correct and also to learn and remember words form. The learner also has to consider target language system.

However, this present study has certain delimitations. First, the study conducted only at writing class. Therefore, the collected data does not vary on other topics. Next, the subject in this study was lack of vocabulary which is resulting words repetition in the texts. Therefore, the present study makes some 
recommendations for researchers who are interested in studying spelling errors of blind student. One recommendation is to conduct the research not only in writing class but also in listening class, reading class and other classes which might yield different results. Furthermore, it will be interesting to find a strategy to help blind students learn spelling. Therefore, the spelling error of blind students can be minimized.

\section{References}

Barraga, N. C., \& Erin, J. N. (1992). Visual handicaps and learning. Austin, TX: PROED.

Barbotte, E., Guillemin, F., \& Chau, N. (2001). Prevalence of impairments, disabilities, handicaps and quality of life in the general population: a review of recent literature. Bulletin of the World Health Organization, 79, 1047-1055.

Budiarti, M. (2018). Factors Influencing Successful Employment for Men with Visual Impairment. IJDS: Indonesian Journal of Disability Studies, 5(1), 81-90.

Clark, C., \& Stoner, J. B. (2008). An investigation of the spelling skills of braille readers. Journal of Visual Impairment \& Blindness, 102(9), 553-563.

Cook, V. J. (2014). The English writing system. Routledge.

Alhaisoni, E. M., Al-Zuoud, K. M., \& Gaudel, D. R. (2015). Analysis of spelling errors of beginner learners of English in the English foreign language context in Saudi Arabia. English Language Teaching, 8(3), 185-192.

Frith, U. (1985). Beneath the surface of developmental dyslexia. Surface dyslexia, 32(1), 301-330.

Mak, Z. (1993). Writing path: Spelling mistakes: Diagnostics and remedial treatment. Jerusalem: Z. Mac [Hebrew].

McCall, S. (1999). Acessing the Curriculum. In C. Arter, L.H. Mason, S. McCall, \& S. Stone (Eds.), Children with visual impairment in mainstream settings (pp.29-40). London: David Fulton.

Stein, V., Neßelrath, R., Alexandersson, J., \& Tröger, J. (2011, May). Designing with and for the Visually Impaired: Vocabulary, Spelling and the Screen Reader. In CSEDU (2) (pp. 462-467).

National Commission on Writing in America's Schools and Colleges. (2003). The neglected " $\mathrm{R}$ ": The need for a writing revolution. The report of the National Commission on Writing in America's Schools and Colleges. Accessed in http://www.collegeboard.com on 1 December 2019 